\title{
MicroRNA-125a-5p regulates liver cancer cell growth, migration and invasion and EMT by targeting HAX1
}

\author{
ZHONGMING ZHA ${ }^{1}$ and JIE $\mathrm{LI}^{2}$ \\ ${ }^{1}$ Department of Hepato-Pancreato-Biliary-Hernial Surgery Ward I, \\ Luoyang Central Hospital Affiliated to Zhengzhou University, Luoyang, Henan 471000; \\ ${ }^{2}$ Department of Hepatobiliary Surgery, Zibo Central Hospital, Zibo, Shandong 255036, P.R. China
}

Received March 12, 2020; Accepted July 29, 2020

DOI: $10.3892 /$ ijmm.2020.4729

\begin{abstract}
To date, the role of hematopoietic-substrate-1-associated protein X-1 (HAX1) in liver cancer is rarely studied. The present study explored the role of HAX1 in liver cancer. The association between HAX1 expression and survival of patients with liver cancer was analyzed by a log-rank test. The target genes for HAX1 was predicted by TargetScan and verified by a dual-luciferase reporter assay. The protein and mRNA expressions of HAX1 in liver cancer and adjacent non-cancerous tissues were examined by immunohistochemistry and reverse transcription-quantitative PCR (RT-qPCR). The transfection efficiency of HAX1, small interfering RNA against HAX1, microRNA (miR)-125a mimics, miR-125a inhibitor, miR-223 mimics and miR-223 inhibitor in liver cancer cells was determined by RT-qPCR. The expression of HAX1, p53, VEGF, epithelial-to-mesenchymal transition (EMT)-related markers (E-cadherin, $\mathrm{N}$-cadherin and vimentin) in the cancer cells were determined by western blotting and RT-qPCR. Cell viability, migration, invasion and colony formation rates were determined by Cell Counting Kot-8, wound healing, Transwell and colony formation assays, respectively. The results showed that high expression of HAX1 in liver cancer was found relate to poor prognosis in patients with liver cancer, and upregulation of HAX1 expression in liver cancer tissues was related to lower overall survival. miR-125a-5p directly binds to HAX1. Upregulation of miR-125a-5p expression inhibited cell viability, migration, invasion and colony formation of SK-Hep1 cells and reduced the expression of HAX1, VEGF, N-cadherin and vimentin, but increased cell apoptosis and the expression of p53 and E-cadherin. However, the effects miR-125a-5p upregulation were partially reversed by
\end{abstract}

Correspondence to: Dr Jie Li, Department of Hepatobiliary Surgery, Zibo Central Hospital, 54 Gongqingtuan West Road, Zibo, Shandong 255036, P.R. China

E-mail: jieli_lijiej@163.com

Key words: hematopoietic-substrate-1-associated protein $\mathrm{X}-1$, microRNA-125a-5p, migration, invasion, epithelial-to-mesenchymal transition
SK-Hep1 cells with HAX1 overexpression. Downregulated miR-125a-5p in SNU-387 cells produced opposite effects, which was partially reversed by HAX silencing. In conclusion, miR-125a-5p suppresses liver cancer growth via targeting HAX1 and concurrently modulating the expression of p53 and VEGF and EMT-related markers.

\section{Introduction}

Liver cancer is one of the most frequently occurring malignant tumors and is the second major cause of tumor-related mortalities worldwide (1). The incidence of liver cancer in China accounts for $55 \%$ of all worldwide cases $(2,3)$. Although strategies of treating liver cancer have improved, including surgical resection, transplantation, ablation, transarterial chemoembolisation, and the tyrosine-kinase inhibitors sorafenib, lenvatinib, and regorafenib (4), the efficacies remain unsatisfactory (5). The recurrence of HCC remains a major problem after curative treatment, reaching an incidence of $>70 \%$ at 5 years $(6,7)$. The development of molecular biology can give rise to improving liver cancer treatment at the molecular level (8).

Hematopoietic cell-specific protein 1-associated protein X-1 (HAX1) is a multifunctional protein $\sim 35 \mathrm{kDa}$ in size and is involved in anti-apoptosis, migration, adhesion and endocytosis regulation (9-11). A previous study found that highly-expressed HAX1 is associated with poor survival in human colorectal cancer (12), cutaneous squamous cell carcinoma (13), laryngeal carcinoma (14) and multiple myeloma (15). Additionally, HAX1 is involved in the metastasis and genesis of various types of tumors (16). Previous studies reported that HAX1 was overexpressed in liver cancer samples $(17,18)$, suggesting that dysregulation of HAX-1 expression plays a key role in liver cancer development. However, the underlying mechanism of HAX1 in the progression of liver cancer and its effects remain unclear.

MicroRNAs (miRs/miRNAs), which are a class of endogenous non-coding genes $\sim 22$ nucleotides in size (19), modulate gene expression by directly binding to the 3 '-untranslated region (3'-UTR) of the target mRNA at the post-transcriptional level (20). MiRNAs can act as oncogenes or tumor suppressors in tumor occurrence and progression, including liver cancer (21-23). It was found that miR-125a-5p is a tumor suppressor in the development of various cancers, including 
in human gastric cancer (24), hepatitis B virus-related liver cancer (25) and gastric cancer (26). Notably, a previous report demonstrated that miR-125a-5p expression is downregulated in liver cancer tissues and cell lines, and lowly expressed miR-125a-5p is correlated with aggressive pathological features (27). However, whether miR-125a-5p participates in the regulation of HAX1 in liver cancer remains to be elucidated.

In the present study, HAX1 expression in liver cancer tissues and cells, and its association with the prognosis of patients with liver cancer were examined. The effects of HAX1 on the development of liver cancer were also explored. Furthermore, the present study determined whether miR-125a-5p was involved in the development of liver cancer via regulating HAX1 expression.

\section{Materials and methods}

Ethics statement. The present study was approved by the Ethics Committee of the Luoyang Central Hospital Affiliated to Zhengzhou University (approval no. LC20170416022). All patients signed informed consent.

Clinical specimens. A total of 40 primary liver tumor tissues and adjacent non-cancerous samples were obtained from patients with liver cancer (age range, 28-75; 22 males; 18 females) who received tumor resection in Luoyang Central Hospital Affiliated to Zhengzhou University between May 2012 and May 2014. All patients with liver cancer did not receive radiotherapy or chemotherapy prior to the surgery.

Cell lines. Human normal liver cell line (THLE-2) and liver cancer cell lines (Hep3B, PLC/PRF/5, SK-Hep1, SNU-182 and SNU-387) were obtained from American Type Culture Collection. The cells were cultured in DMEM (cat. no. 12100; Beijing Solarbio Science \& Technology Co., Ltd.) supplemented with 10\% FBS (cat. no. 11011-8611; Beijing Solarbio Science \& Technology Co., Ltd.) and penicillin-streptomycin liquid $(100 \mathrm{U} / \mathrm{ml}$ penicillin, $100 \mathrm{mg} / \mathrm{ml}$ streptomycin; cat. no. P1400; Beijing Solarbio Science \& Technology Co., Ltd.) at $37^{\circ} \mathrm{C}$ with $5 \% \mathrm{CO}_{2}$.

Cell transfection. To construct plasmids expressing HAX1, the full-length human HAX1 sequence was synthesized by Guangzhou RiboBio Co., Ltd. and ligated into the pcDNA3.1 plasmid (cat. no. V79020; Thermo Fisher Scientific, Inc.). For cell transfection, $2 \mathrm{mg} / \mathrm{ml} \mathrm{HAX1}$ vector, $50 \mathrm{pmol} / \mathrm{ml} \mathrm{miR-125a}$ mimics (cat. no. miR10000443-1-5; Guangzhou RiboBio Co., Ltd.), $50 \mathrm{pmol} / \mathrm{ml} \mathrm{mimics} \mathrm{negative} \mathrm{control} \mathrm{(mimics} \mathrm{NC;} \mathrm{cat.}$ no. miR1N0000001-1-5; Guangzhou RiboBio Co., Ltd.), $50 \mathrm{pmol} / \mathrm{ml} \mathrm{miR}-223$ mimics (cat. no. miR10000280-1-5; Guangzhou RiboBio Co., Ltd.), $50 \mathrm{pmol} / \mathrm{ml} \mathrm{miR-125a}$ inhibitor (cat. no. miR20000443-1-5; Guangzhou RiboBio Co., Ltd.), $50 \mathrm{pmol} / \mathrm{ml}$ inhibitor NC (cat. no. miR2N0000001-1-5; Guangzhou RiboBio Co., Ltd.), small interfering RNA (siRNA) against HAX1 (siHAX1; cat. no. siG000010456A-1-5; Guangzhou RiboBio Co., Ltd.) and siRNA negative control (siNC; cat. no. siN0000002-1-5, Guangzhou RiboBio Co., Ltd.) were transfected into SK-Hep1 and SNU-387 cells. Cell transfection was conducted using Lipofectamine ${ }^{\mathrm{TM}} 2000$ (cat. no. 11668; Invitrogen; Thermo Fisher Scientific, Inc.).
Table I. Primer sequences used for reverse transcriptionquantitative PCR.

\begin{tabular}{ll}
\hline Gene & \multicolumn{1}{c}{ Primer sequences (5'-3') } \\
\hline HAX1 & F: CAGGAGGAGGGATACGTTCC \\
miR-125a-5p & R: CCCATATCGCTGAAGATGCTATT \\
& RT: 5'-GTCGTATCCAGTGCGTGTCG \\
& TGGAGTCGGCAATTGCACTGGATA \\
& CGACTCACAGGT-3' \\
& F: TGTGAGTCGTATCCAGTGCAA \\
& R: GTATCCAGTGCGTGTCGTGG \\
miR-223-3p & F: CCCAGTCGTATCCAGTGCAA \\
& R: GTCGTATCCAGTGCGTGTCG \\
p53 & F: CAGCACATGACGGAGGTTGT \\
VEGF & R: TCATCCAAATACTCCACACGC \\
& F: AGGGCAGAATCATCACGAAGT \\
E-cadherin & R: AGGGTCTCGATTGGATGGCA \\
& F: CGAGAGCTACACGTTCACGG \\
N-cadherin & R: GGGTGTCGAGGGAAAAATAGG \\
Vimentin & F: TCAGGCGTCTGTAGAGGCTT \\
& R: ATGCACATCCTTCGATAAGACTG \\
FADPH & F: GACGCCATCAACACCGAGTT \\
& F: CTTGTCGTTGGTTAGCTGGT \\
U6 & R: GGCTGTTGTCATACTTCTCATGG \\
& F: CTCGCTTCGGCAGCACA \\
& R: ACGCTTCACGAATTTGCGT
\end{tabular}

HAX1, hematopoietic-substrate-1-associated protein X-1; miR, microRNA; F, forward; R, reverse; RT, reverse transcription.

In addition, untreated cells were used as control. SNU-387 cells transfected with pcDNA3.1 empty plasmid were used as the NC group, while SK-Hep1 cells transfected with siRNA negative control used as the siNC group.

Prognosis analysis. The association between patient survival and HAX1 expression in patients with liver cancer was plotted using Kaplan-Meier curves and log-rank tests based on data obtained from Kaplan-Meir Plotter (http://kmplot.com/analysis/index.php?p=service \& cancer=liver_rnaseq) (28) and data from follow-up time (60 months).

Immunohistochemistry. Immunohistochemistry was performed as previously described (29). The sections were incubated with primary antibody against HAX1 (rabbit; cat. no. ab137613; 1:1,000; Abcam) overnight at $4^{\circ} \mathrm{C}$ followed by secondary antibody incubation (goat anti-rabbit; cat. no. ab205718; 1:2,000; Abcam). The sections were dyed with 3,3-diaminobenzidine horseradish peroxidase color development kit (cat. no. P0203; Beyotime Institute of Biotechnology), counter-stained with hematoxylin, added to coverslips and observed under a light microscope (Olympus Corporation).

Reverse transcription-quantitative real-time $P C R$ $(R T-q P C R)$. Total RNAs were extracted from the collected 
Table II. List of primary antibodies used for western blotting.

\begin{tabular}{llcll}
\hline Protein & \multicolumn{1}{c}{ Antibody } & Cat. no. & Company & Antibody dilution \\
\hline HAX1 & Rabbit anti-HAX1 antibody & ab78939 & Abcam & $1: 1,000$ \\
p53 & Mouse anti-p53 antibody & ab26 & Abcam & $1: 1,000$ \\
E-cadherin & Rabbit anti-E-cadherin antibody & ab40772 & Abcam & $1: 500$ \\
VEGF & Rabbit anti-VEGF antibody & ab1316 & Abcam & $1: 1,000$ \\
N-cadherin & Rabbit anti-N-cadherin antibody & ab18203 & Abcam & $1: 1,000$ \\
Vimentin & Rabbit anti-vimentin antibody & ab92547 & Abcam & $1: 1,000$ \\
GAPDH & Mouse anti-GAPDH antibody & ab8245 & Abcam & $1: 1,000$ \\
\hline
\end{tabular}

HAX1, hematopoietic-substrate-1-associated protein X-1.

tissues and cells (SK-Hep1 and SNU-387) using TRIzol ${ }^{\circledR}$ reagent (Invitrogen; Thermo Fisher Scientific, Inc.). The reverse transcription of non-miRNAs was performed using the PrimeScript RT reagent kit (cat. no. RR036B; Takara Bio, Inc.) according to the manufacturer's instructions. The reverse transcription of miRNAs was performed using a stem-loop RT primer and the PrimeScript RT reagent kit (Takara Bio, Inc.) according to the manufacturer's instructions. cDNAs were amplified on a 7500 Fast Real-Time PCR system (Applied Biosystems; Thermo Fisher Scientific, Inc.) using TB Premix Ex Taq (cat. no. RR820L; Takara Bio, Inc.). The following thermocycling conditions were used for the qPCR: Initial denaturation at $94^{\circ} \mathrm{C}$ for $30 \mathrm{sec}$, followed by 40 cycles of denaturation at $94^{\circ} \mathrm{C}$ for $5 \mathrm{sec}$, annealing at $55^{\circ} \mathrm{C}$ for $30 \mathrm{sec}$ and final extension at $72^{\circ} \mathrm{C}$ for $30 \mathrm{sec}$. Gene expression was normalized to GAPDH or U6 as appropriate (Sangon Biotech Co., Ltd.). The expression was calculated and quantified using the $2^{-\Delta \Delta \mathrm{Cq}}$ method (30). The primer sequences are listed in Table I.

Western blotting. Total proteins were extracted from the tissues and cells (SK-Hepl and SNU-387) using RIPA buffer (cat. no. R0010; Beijing Solarbio Science \& Technology Co., Ltd.). Protein concentration was detected using a BCA protein assay kit (cat. no. PC0020; Beijing Solarbio Science $\&$ Technology Co., Ltd.). Whole cell lysates $(30 \mu \mathrm{g} / \mathrm{lane})$ were separated by $12.5 \%$ SDS-PAGE and then transferred to PVDF membranes (cat. no. FFP32; Beyotime Institute of Biotechnology) with an electroblotting apparatus. Subsequently, the membranes were incubated in $5 \%(\mathrm{w} / \mathrm{v})$ skimmed milk for $1 \mathrm{~h}$ at $37^{\circ} \mathrm{C}$ to block non-specific binding, and then treated with the appropriate primary antibodies overnight at $4^{\circ} \mathrm{C}$ (Table II). The membranes were then treated with goat anti-mouse secondary antibody (cat. no. ab205719; Abcam) or goat anti-rabbit secondary antibody (cat. no. ab205718; Abcam) at $1: 2,000$ dilution for $1 \mathrm{~h}$ at $37^{\circ} \mathrm{C}$. Protein signals were visualized using an ECL detection kit (cat. no. P0018FS; Beyotime Institute of Biotechnology) and normalized to GAPDH. The target bands were visualized by a gel documentation system (C-DiGit Blot Scanner; LI-COR Biosciences).

Cell Counting Kit-8 (CCK-8) assay. Cell viability was detected using a CCK-8 kit (cat. no. CK04; Dojindo Molecular Technologies, Inc.) according to the manufacturer's protocol.
Transfected SK-Hep1 and SNU-387 cells (1x10 ${ }^{4}$ cell/well) were cultured in 96-well plates containing DMEM at $37^{\circ} \mathrm{C}$ with $5 \% \mathrm{CO}_{2}$ for 0,24 and $48 \mathrm{~h}$. CCK-8 solution $(10 \mathrm{ml})$ was added into the cells and incubated for another $4 \mathrm{~h}$. A microplate reader (Sunrise Microplate Reader; Tecan Group, Ltd.) was used to detect the absorbance at a wavelength of $450 \mathrm{~nm}$.

Scratch wound healing assay. Cell migration was determined using a scratch wound-healing assay. In brief, the SK-Hep1 and SNU-387 cells were cultured in six-well plates to $80 \%$ confluence. Subsequently, DMEM was discarded and the cells in the six-well plates were scratched with a $10-\mu 1$ tip and incubated with serum-free DMEM. The cells were further cultured for $24 \mathrm{~h}$. Cell migration was analyzed by counting migrated cells under an inverted microscope (x100 magnification; Ts2R-FL; Nikon Corporation) using ImageJ 1.8.0 (National Institutes of Health).

Transwell invasion assay. Cell invasion was detected using a Transwell assay. In brief, transfected SK-Hep1 and SNU-387 cells $\left(5 \times 10^{5}\right.$ cell/well $)$ were added into the upper chamber (precoated with Matrigel matrix), which contained $200 \mathrm{ml}$ DMEM without serum, while the lower Transwell chamber contained with $600 \mu \mathrm{l}$ DMEM supplemented with $20 \%$ FBS. Following culture for $24 \mathrm{~h}$, non-invasive cells remaining in the upper chamber were gently scraped off with cotton swabs, while the medium in the lower chamber were aspirated. Cells were fixed with $4 \%$ paraformaldehyde for $15 \mathrm{~min}$ at room temperature and stained with $0.1 \%$ crystal violet for $20 \mathrm{~min}$ at room temperature. Cells were counted from five random fields under an inverted microscope (x200 magnification; Ts2R-FL; Nikon Corporation).

Colony formation unit assay. SK-Hep1 and SNU-387 cells were seeded into six-well plates at a density of $1 \times 10^{3}$ cells/well. DMEM was replaced every 4 days. After culture for 14 days, the cells were fixed with $4 \%$ paraformaldehyde for $15 \mathrm{~min}$ at room temperature and stained with crystal violet for $15 \mathrm{~min}$ at room temperature. The cell clones were photographed using a camera (Nikon D90; Nikon Corporation) and the relative colony formation rates were calculated.

Cell apoptosis detection. The apoptosis of SK-Hep1 and SNU-387 cells was determined by flow cytometry using an 

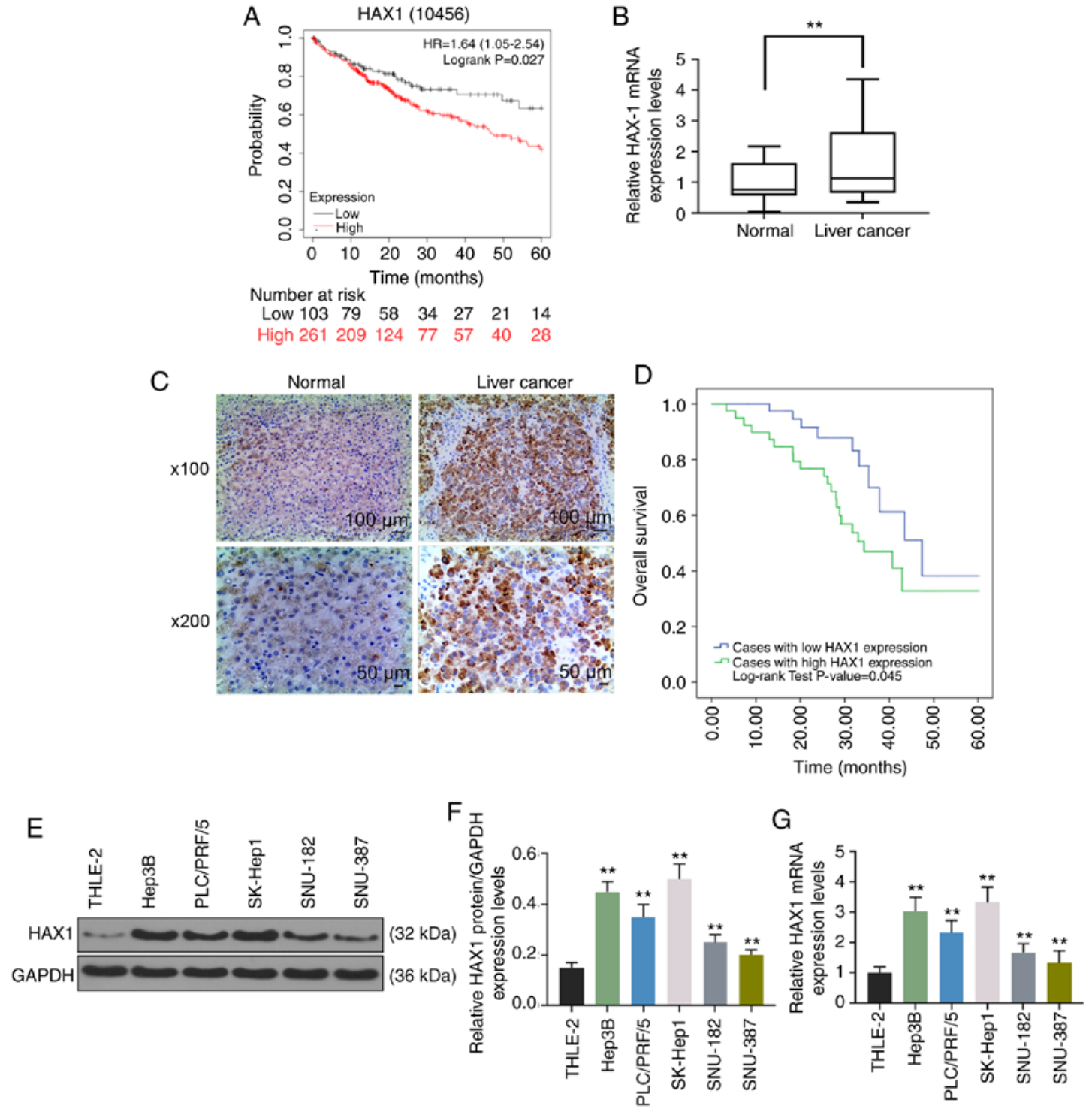

Figure 1. HAX1 is overexpressed in liver cancer tissues and cells and associated with patient prognosis. (A) The association between HAX1 expression and overall survival of patients with liver cancer was analyzed based on data from Kaplan-Meier Plotter. (B) HAX1 expression in liver cancer tissues and adjacent normal tissues was determined by RT-qPCR. ${ }^{* *} \mathrm{P}<0.01$ vs. normal. (C) HAX1 protein in liver cancer tissues and adjacent normal tissues was stained by immunohistochemistry. (D) The association between overall survival and HAX1 in patients with liver cancer was analyzed based on data from follow-up time (60 months). (E and F) HAX1 protein expression in human normal liver cell line THLE-2 and human liver cancer cell lines (Hep3B, PLC/PRF/5, SK-Hep1, SNU-182 and SNU-387) was determined by western blotting. ${ }^{* *} \mathrm{P}<0.01$ vs. THLE-2. (G) HAX1 mRNA levels in human normal liver cell line THLE-2 and human liver cancer cell lines (Hep3B, PLC/PRF/5, SK-Hep1, SNU-182 and SNU-387) was determined by RT-qPCR. GAPDH was used as an internal control. ${ }^{* *} \mathrm{P}<0.01$ vs. THLE-2. Data are shown as the mean \pm standard deviation. HAX1, hematopoietic-substrate-1-associated protein X-1; RT-qPCR, reverse transcription-quantitative PCR; HR, hazard ratio.

Annexin V/PI kit (cat. no. KGA108; Nanjing KeyGen Biotech Co., Ltd.) according to the manufacturer's instructions. In brief, treated SK-Hep1 and SNU-387 cells were collected and incubated with Annexin V/PI for 15 min at room temperature in the dark. Finally, the fluorescence of cells was detected and analyzed by fluorescence-activated cell sorting (FACSCalibur; BD Biosciences).

Dual-luciferase activity assay. TargetScan (http://www. targetscan.org/vert_72/) predicted that miR-125a-5p and miR-223-3p were the target genes for HAX1. The sequence of the 3'-UTR of HAX1 with the binding sites for has-miR-125a-5p or has-miR-223-3p was synthesized by Guangzhou RiboBio Co., Ltd. and cloned into a luciferase reporter gene vector (cat. no. E1330; Promega Corporation). In this experiment, the mutation (mut) refers to the change of sequence of the putative binding site of HXA1 in miR-125a-5p or miR-223-3p. HXA1-mut contained a mutation in the predicted binding sites of miR-125a-5p or miR-223-3p. The sequence of HXA1-mut was as follows: 5'-AGCUUCUCUUGCCACCUA GCCAG-3' or 5'-UUUGUCACUCACCCAAAGGCGC-3'. The HAX1-3'-UTR mut was purchased from Guangzhou RiboBio Co., Ltd. and cloned into a luciferase reporter gene vector (cat. no. E1330; Promega Corporation). For the dual-luciferase reporter assay, the reporter vector plasmid and miR-125a mimics or miR-223 mimics were co-transfected into 293T cells (cat. no. CRL-11268; American Type Culture Collection) using Lipofectamine ${ }^{\mathrm{TM}} 2000$ (cat. no. 11668; 
A

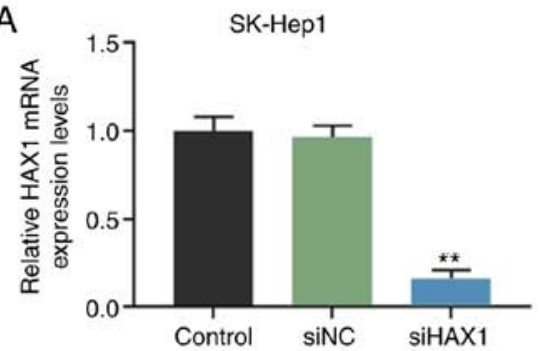

B

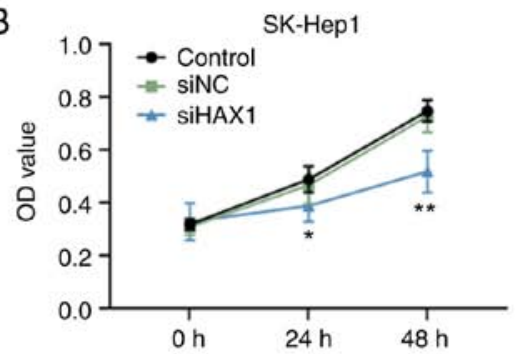

C
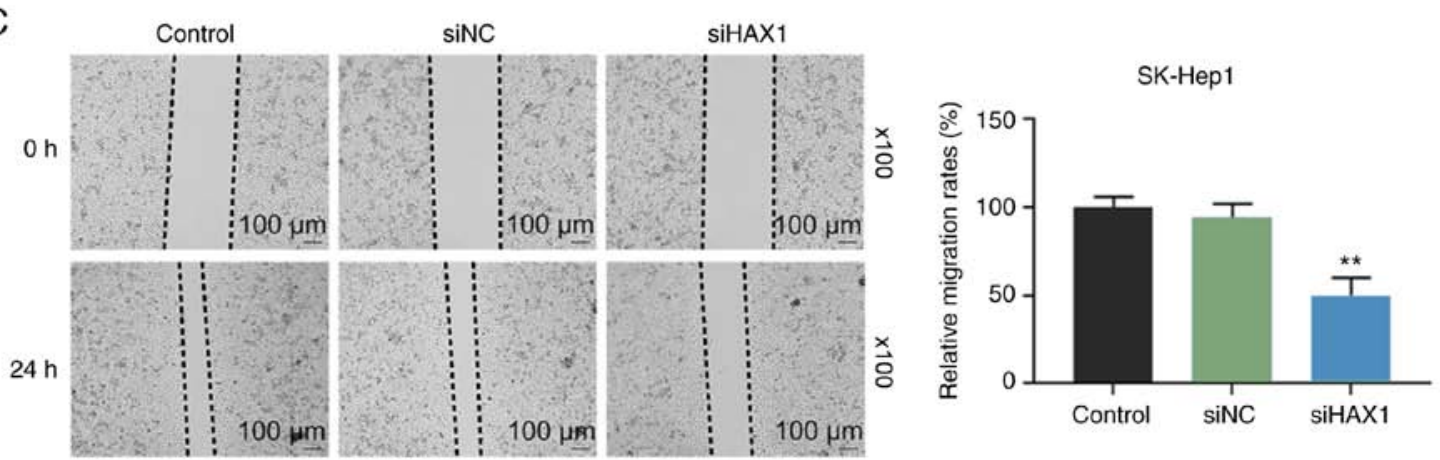

D
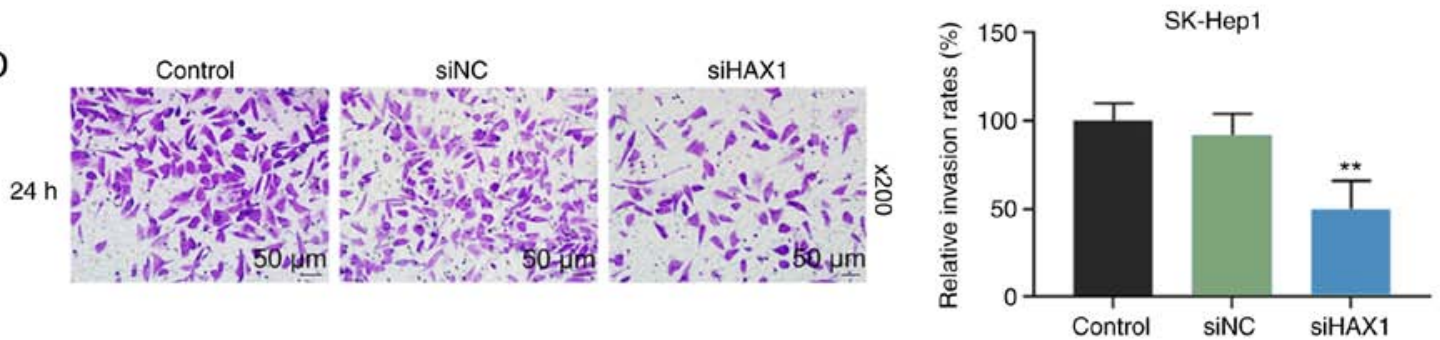

$\mathrm{E}$
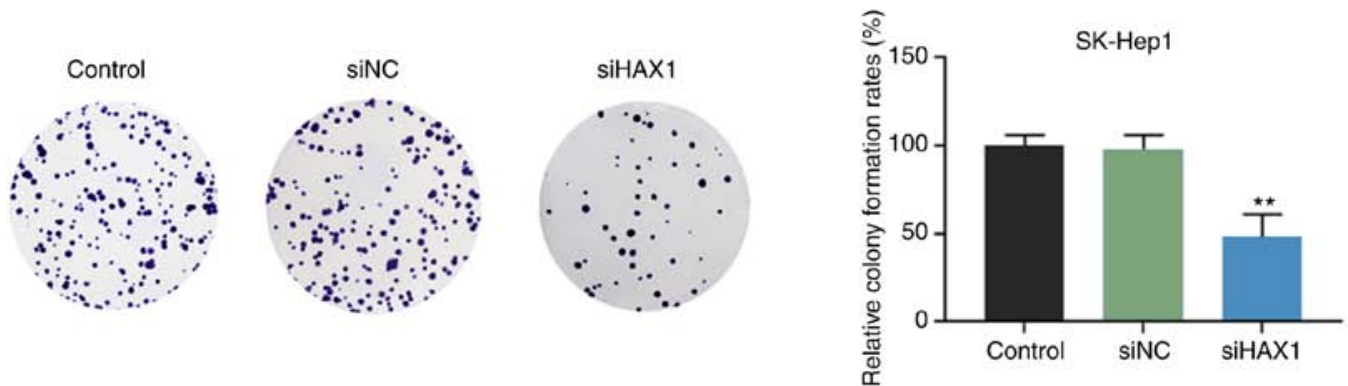

Figure 2. HAX1 silencing suppresses cell viability, migration, invasion and colony formation of SK-Hep1 cells. (A) SK-Hep1 cells were divided into Control (untreated), siNC (transfected with siRNA negative control) and siHAX1 (transfected with HAX1-target-siRNA) groups. The transfection efficiency of siHAX1 was detected by reverse transcription-quantitative PCR. (B) Relative cell viability was determined using a Cell Counting Kit-8 assay at 0 , 24 and 48 h. (C) Cell migration was determined by scratch wound-healing assay. (D) Cell invasion was determined by Transwell invasion assay. (E) Cell colony numbers were determined by colony formation assay. ${ }^{*} \mathrm{P}<0.05$ and ${ }^{* *} \mathrm{P}<0.01$ vs. siNC. Data are shown as the mean \pm standard deviation. HAX1, hematopoietic-substrate-1-associated protein $\mathrm{X}-1$; si, small interfering RNA; NC, negative control; OD, optical density.

Invitrogen; Thermo Fisher Scientific, Inc.). Following transfection for $48 \mathrm{~h}$, the luciferase activities of different groups were measured using the Dual-Luciferase Reporter Assay system (cat. no. E1910; Promega Corporation). The luciferase activities were normalized to Renilla luciferase activity.

Statistical analysis. The data are represented as the mean \pm SD and analyzed using SPSS 19.0 software (IBM Corp.). Kaplan-Meier plots were analyzed with log-rank test. Paired t-test was used for analysis of paired samples. Comparison between two groups was performed by Student's t-test, whereas comparison among multiple groups was performed by one-way ANOVA analysis followed by Tukey's post hoc test. $\mathrm{P}<0.05$ was considered to indicate a statistically significant difference.

\section{Results}

High HAX1 expression is observed in liver cancer tissues and cells and associated with prognosis of patients. Based analysis of data obtained from Kaplan-Meier Plotter (http://kmplot.com/analysis/index. php? $=$ =service\&cancer=liver_rnaseq), Kaplan-Meier plots revealed that high HAX1 expression in liver cancer cases was associated with lower overall survival compared with low HAX1 expression (Fig. 1A; P<0.05), and HAX1 showed significantly higher expression in liver cancer tissues compared with normal tissues (Fig. 1B; P<0.01). HXA1 protein staining from two representative cases are shown in Fig. 1C. 
A

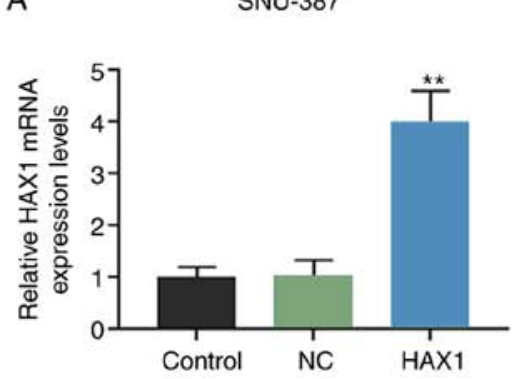

B

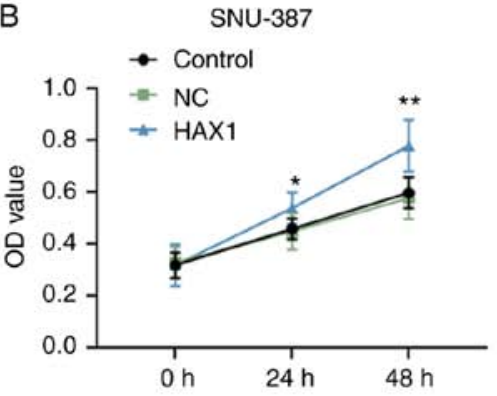

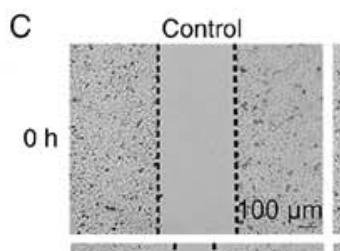
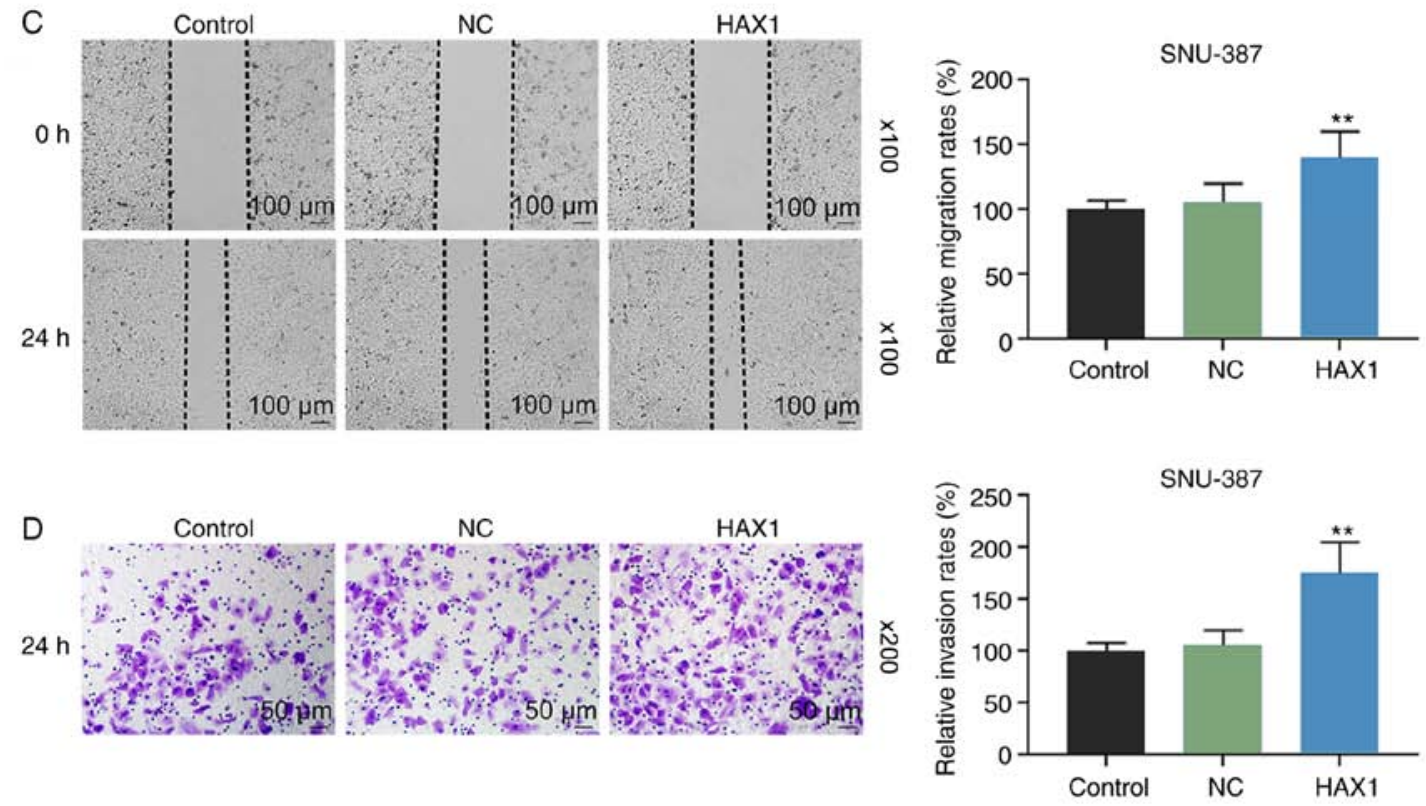

E
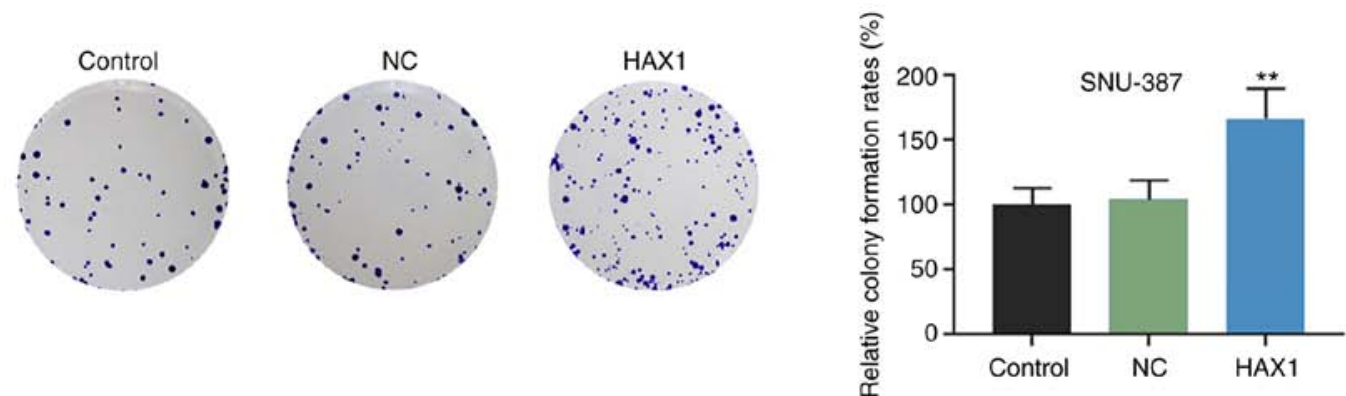

Figure 3. HAX1 overexpression promotes cell viability, migration, invasion and colony formation of SNU-387 cells. (A) SNU-387 cells were divided into Control (untreated), NC (transfected with pcDNA3.1 empty plasmid) and HAX1 (transfected with pcDNA3.1-HAX1) groups. The transfection efficiency of pc-HAX1 was evaluated by reverse transcription-quantitative PCR. (B) Relative cell viability was determined using a Cell Counting Kit- 8 assay at 0,24 and 48 h. (C) Cell migration was determined by scratch wound-healing assay. (D) Cell invasion was determined by Transwell invasion assay. (E) Cell colony numbers were determined by colony formation assay. ${ }^{*} \mathrm{P}<0.05$ and $^{* *} \mathrm{P}<0.01 \mathrm{vs.}$. NC. Data are shown as the mean \pm standard deviation. HAX1, hematopoietic-substrate-1-associated protein $\mathrm{X}-1 ; \mathrm{NC}$, negative control; OD, optical density.

The overall survival of liver cancer patients with high HAX1 expression was significantly lower compared with patients with low HAX1 expression (Fig. 1D; P<0.05) obtained from Luoyang Central Hospital Affiliated to Zhengzhou University. Additionally, significantly higher protein (Fig. 1E and F; P<0.01) and mRNA (Fig. 1G; P<0.01) expression of HAX1 were observed in human liver cancer cell lines (Hep3B, PLC/PRF/5, SK-Hep1, SNU-182 and SNU-387) compared with human normal liver cell line THLE-2. HAX1 expression was lower in SNU-387 cells compared with other liver cancer cell lines (Fig. 1E-G), while HAX1 expression was higher in SK-Hep1 cells than other liver cancer cell lines
(Fig. 1E-G). Therefore, SNU-387 and SK-Hep1 cells were used in the following experiments.

HAX1 silencing suppresses the viability, migration, invasion and colony formation of SK-Hepl cells. To determine the biological role of HAX1 in the development of liver cancer, SK-Hep1 cells were transfected with siHAX1 to downregulate HAX1 expression. RT-qPCR results showed that HAX1 expression was significantly lower in the siHAX1 group compared with the siNC group (Fig. 2A; $\mathrm{P}<0.01$ ). As shown in Fig. 2B-E, compared with the siNC group, HAX1 silencing significantly suppressed the cell viability at 24 and 

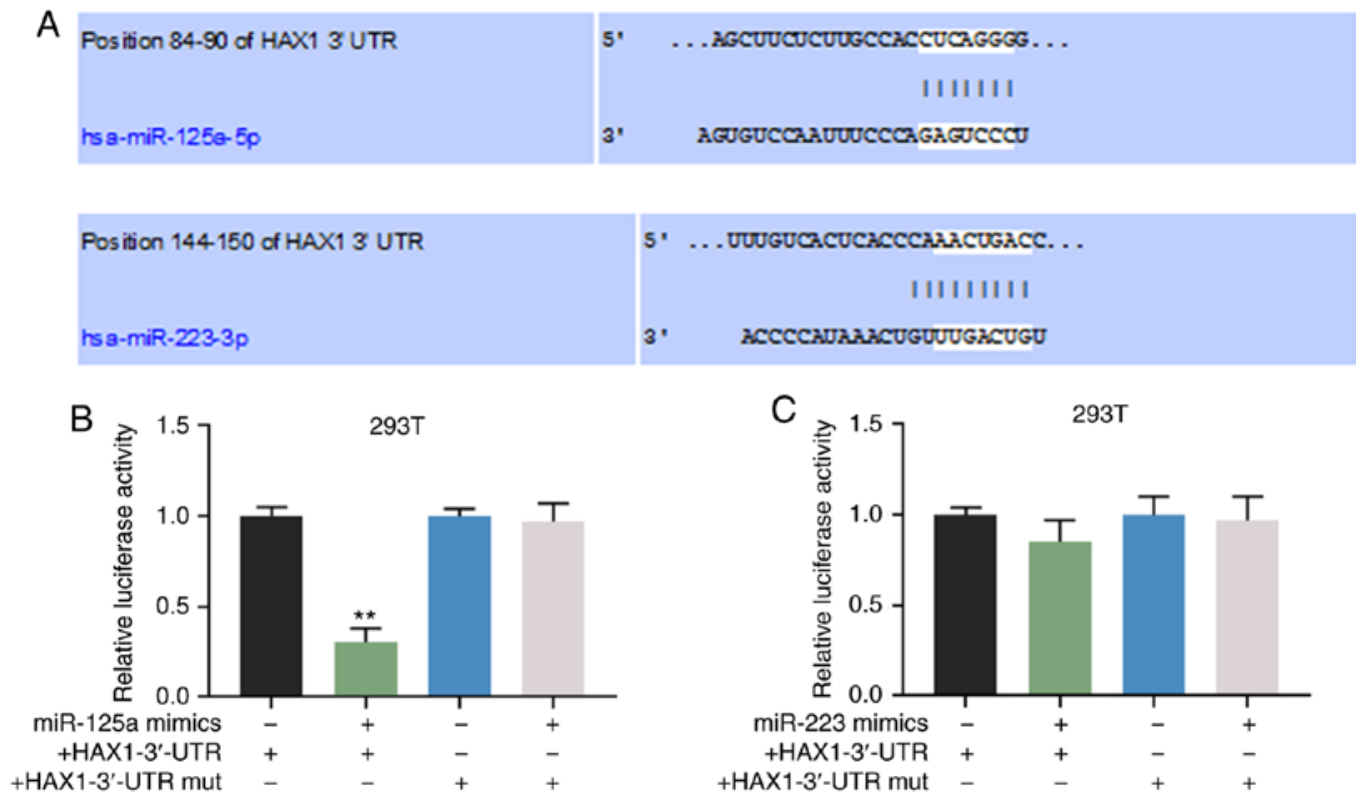

Figure 4. HAX1 is the target of miR-125a-5p. (A) HAX-1 was predicted to be a target of miR-125a-5p and miR-223-3p by the TargetScan database. (B) The luciferase activity of 293T cells co-transfected with (B) wild-type/mutant 3'-UTR of HAX1 (HAX1-3'-UTR/HAX1-3'-UTR mut) and miR-125a mimics and (C) wild-type/mutant 3'-UTR of HAX1 (HAX1-3'-UTR/HAX1-3'-UTR mut) and miR-223 mimics was determined using a dual-luciferase reporter assay. ${ }^{* *} \mathrm{P}<0.01$ vs. control (cells transfected with HAXA-3'-UTR alone). Data are shown as the mean \pm standard deviation. HAX1, hematopoietic-substrate-1-associated protein X-1; miR, microRNA; 3'-UTR, 3'-untranslated region; mut, mutant.

A $\quad$ Mimics NC $\quad$ B miR-125a mimics

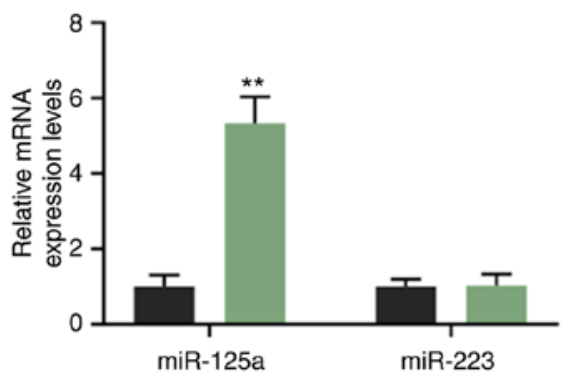

C

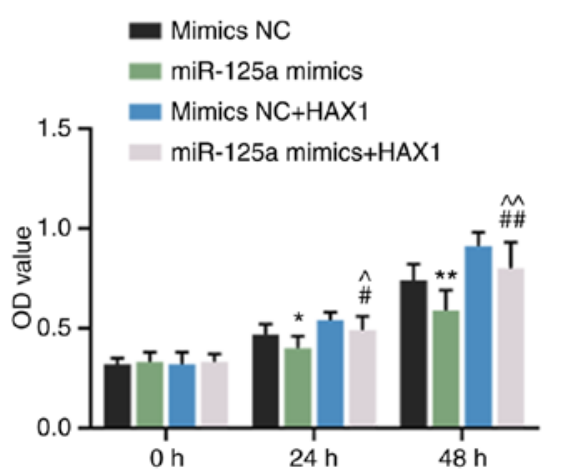

B
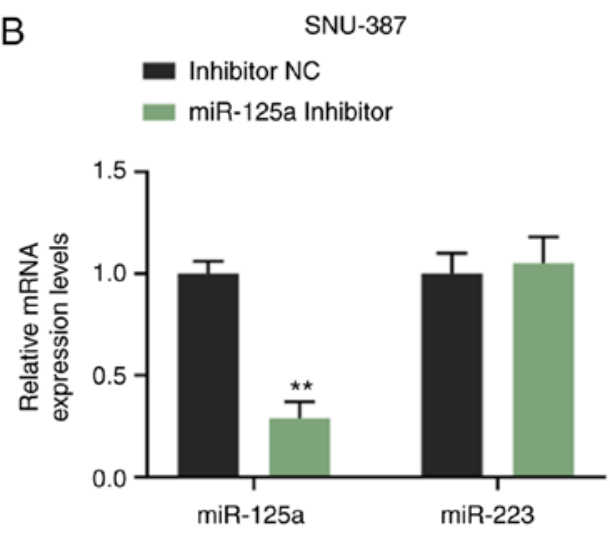

D

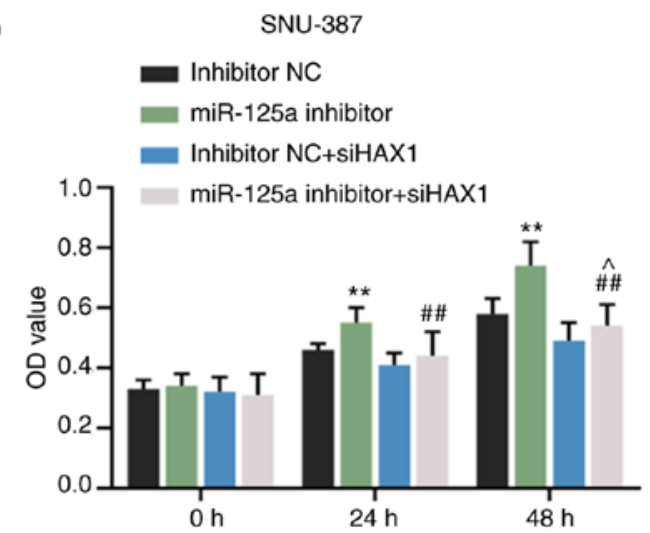

Figure 5. HAX1 reverses the effects of miR-125a on cell viability. (A) The effects of miR-125a mimics on the expression of miR-125a and miR-223 normalized to U6 in SK-Hep1 cells was determined by RT-qPCR. " P<0.01 vs. mimic NC. (B) The effects of miR-125a inhibitor on the expression of miR-125a and miR-223 normalized to U6 in SNU-387 cells was determined by RT-qPCR. ** P<0.01 vs. inhibitor NC. (C) The viability of SK-Hep1 cells transfected with miR-125a mimics or HAX1 or co-transfected with miR-125a mimics and HAX1 was determined using a Cell Counting Kit-8 assay. "P $<0.05$ and ${ }^{* *} \mathrm{P}<0.01$ vs. mimics NC. ${ }^{\#} \mathrm{P}<0.05$ and ${ }^{\# \#} \mathrm{P}<0.01$ vs. miR-125a mimics. ${ }^{\wedge} \mathrm{P}<0.05$ and ${ }^{\wedge} \mathrm{P}<0.01$ vs. mimics NC $+\mathrm{HAX} 1$. (D) The viability of SNU-387 cells transfected with miR-125a inhibitor or siHAX1 or co-transfected with miR-125a inhibitor and siHAX1 was determined using a Cell Counting Kit-8 assay. ${ }^{* *} \mathrm{P}<0.01$ vs. inhibitor NC. ${ }^{\# \#} \mathrm{P}<0.01$ vs. miR-125a inhibitor. ${ }^{\wedge} \mathrm{P}<0.05$ vs. inhibitor $\mathrm{NC}+\mathrm{siHAX} 1$. Data are shown as the mean \pm standard deviation. HAX1, hematopoietic-substrate-1-associated protein X-1; miR, microRNA; RT-qPCR, reverse transcription-quantitative PCR; OD, optical density; si, small interfering RNA; NC, negative control. 
A
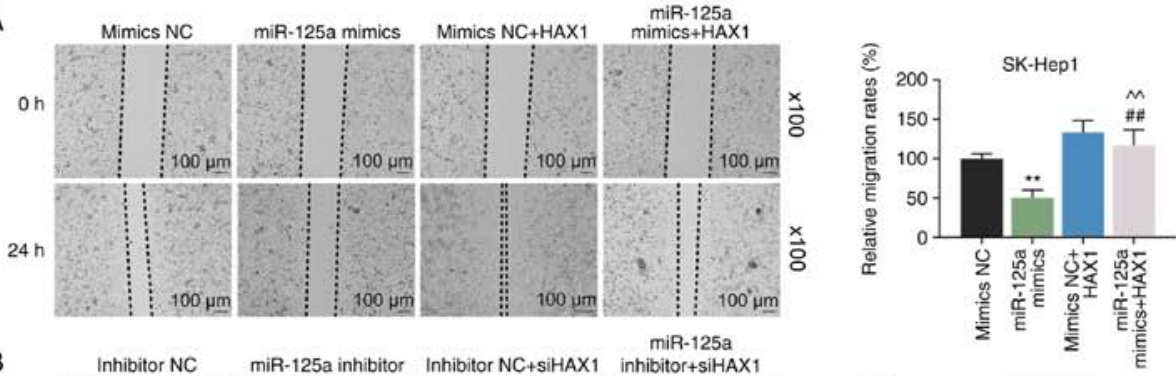

B
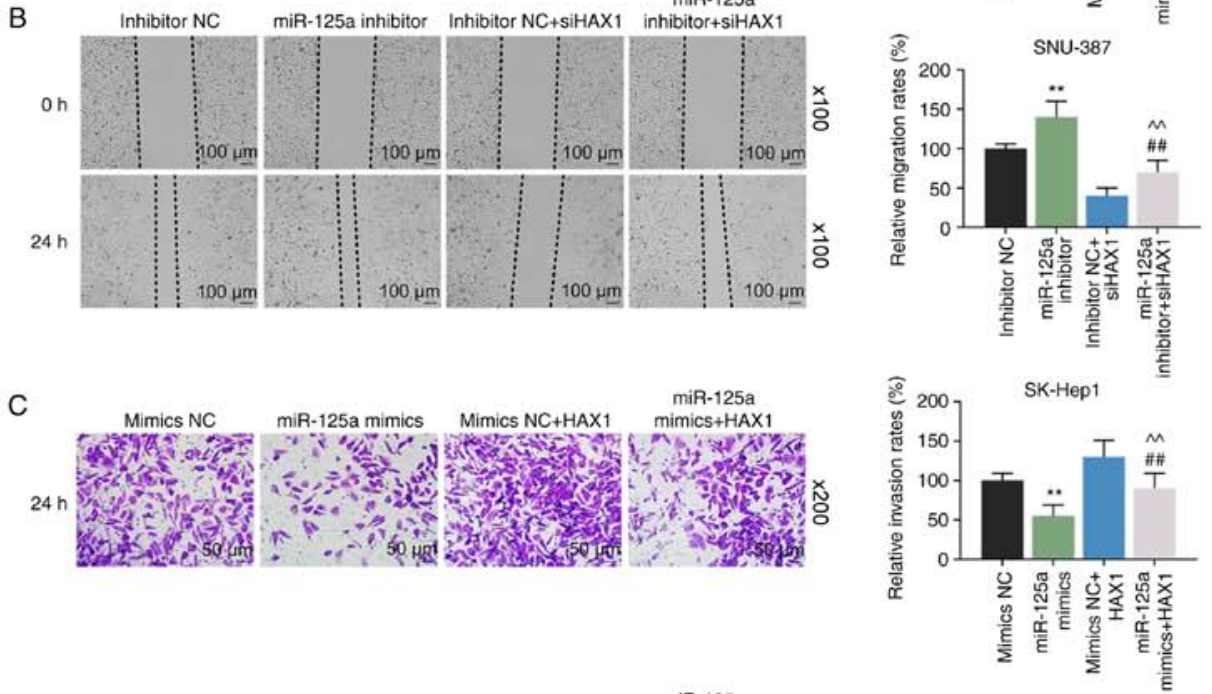

D
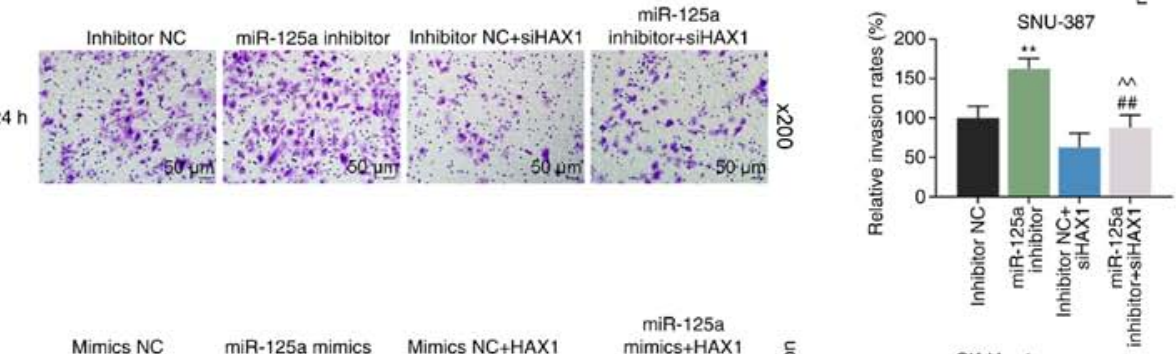

E
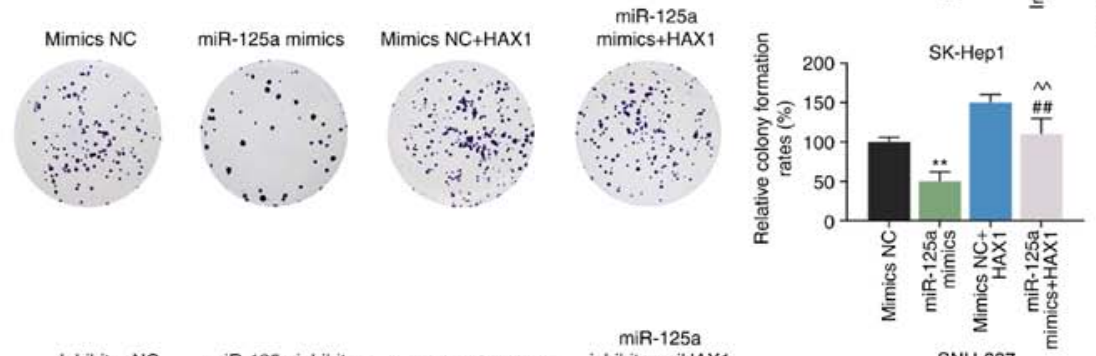

SK-Hep1

$\mathrm{F}$
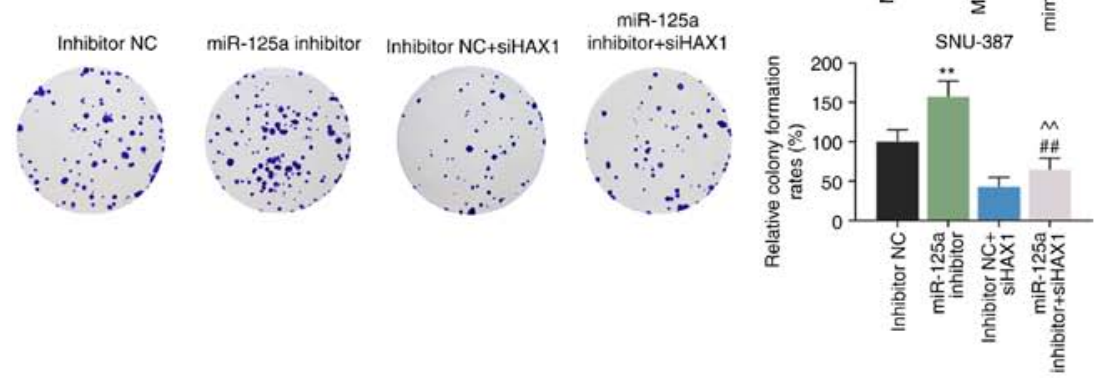

Figure 6. HAX1 reverses the effects of miR-125a on cell migration, invasion and colony formation. (A) The migration of SK-Hep1 cells transfected with miR-125a mimics or HAX1 or co-transfected with miR-125a mimics and HAX1 was determined by scratch wound-healing assay. ${ }^{* *} \mathrm{P}<0.01 \mathrm{vs.}$ mimics NC. ${ }^{\# \#} \mathrm{P}<0.01$ vs. miR-125a mimics. ${ }^{\wedge} \mathrm{P}<0.01$ vs. mimics NC + HAX1. (B) The migration of SNU-387 cells transfected with miR-125a inhibitor or HAX1 or co-transfected with miR-125a inhibitor and siHAX1 was determined by scratch wound-healing assay. ${ }^{* *} \mathrm{P}<0.01$ vs. inhibitor NC. ${ }^{\# \#} \mathrm{P}<0.01 \mathrm{vs}$. miR-125a inhibitor. ${ }^{\wedge} \mathrm{P}<0.01$ vs. inhibitor NC + siHAX1. (C) The invasion of SK-Hep1 cells transfected with miR-125a mimics or HAX1 or co-transfected with miR-125a mimics and HAX1 was determined by Transwell invasion assay. ${ }^{* *} \mathrm{P}<0.01$ vs. mimics NC. ${ }^{\# \#} \mathrm{P}<0.01$ vs. miR-125a mimics. ${ }^{\wedge} \mathrm{P}<0.01$ vs. mimics NC $+\mathrm{HAX} 1$. (D) The invasion of SNU-387 cells transfected with miR-125a inhibitor or siHAX1 or co-transfected with miR-125a inhibitor and siHAX1 was determined by Transwell invasion assay. ${ }^{* *} \mathrm{P}<0.01$ vs. inhibitor NC. ${ }^{\# \#} \mathrm{P}<0.01$ vs. miR-125a inhibitor. ${ }^{\wedge} \mathrm{P} 0.01$ vs. inhibitor NC + siHAX1. (E) Cell colony numbers were determined using a colony formation assay following transfection of SK-Hep1 cells with miR-125a mimics or HAX1 or co-transfection with miR-125a mimics and HAX1. ${ }^{* *} \mathrm{P}<0.01$ vs. mimics NC. ${ }^{\# \#} \mathrm{P}<0.01$ vs. miR-125a mimics. ${ }^{\wedge} \mathrm{P}<0.01$ vs. mimics NC + HAX1. (F) Cell colony numbers were determined by colony formation assay following transfection of SNU-387 cells with miR-125a inhibitor or siHAX1 or co-transfection with miR-125a inhibitor and siHAX1. ${ }^{* *} \mathrm{P}<0.01$ vs. inhibitor NC. ${ }^{\# \#} \mathrm{P}<0.01$ vs. miR-125a inhibitor. ${ }^{\wedge} \mathrm{P} 0.01$ vs. inhibitor $\mathrm{NC}+\mathrm{siHAX} 1$. Data are shown as the mean \pm standard deviation. HAX1, hematopoietic-substrate-1-associated protein X-1; miR, microRNA; si, small interfering RNA; NC, negative control. 

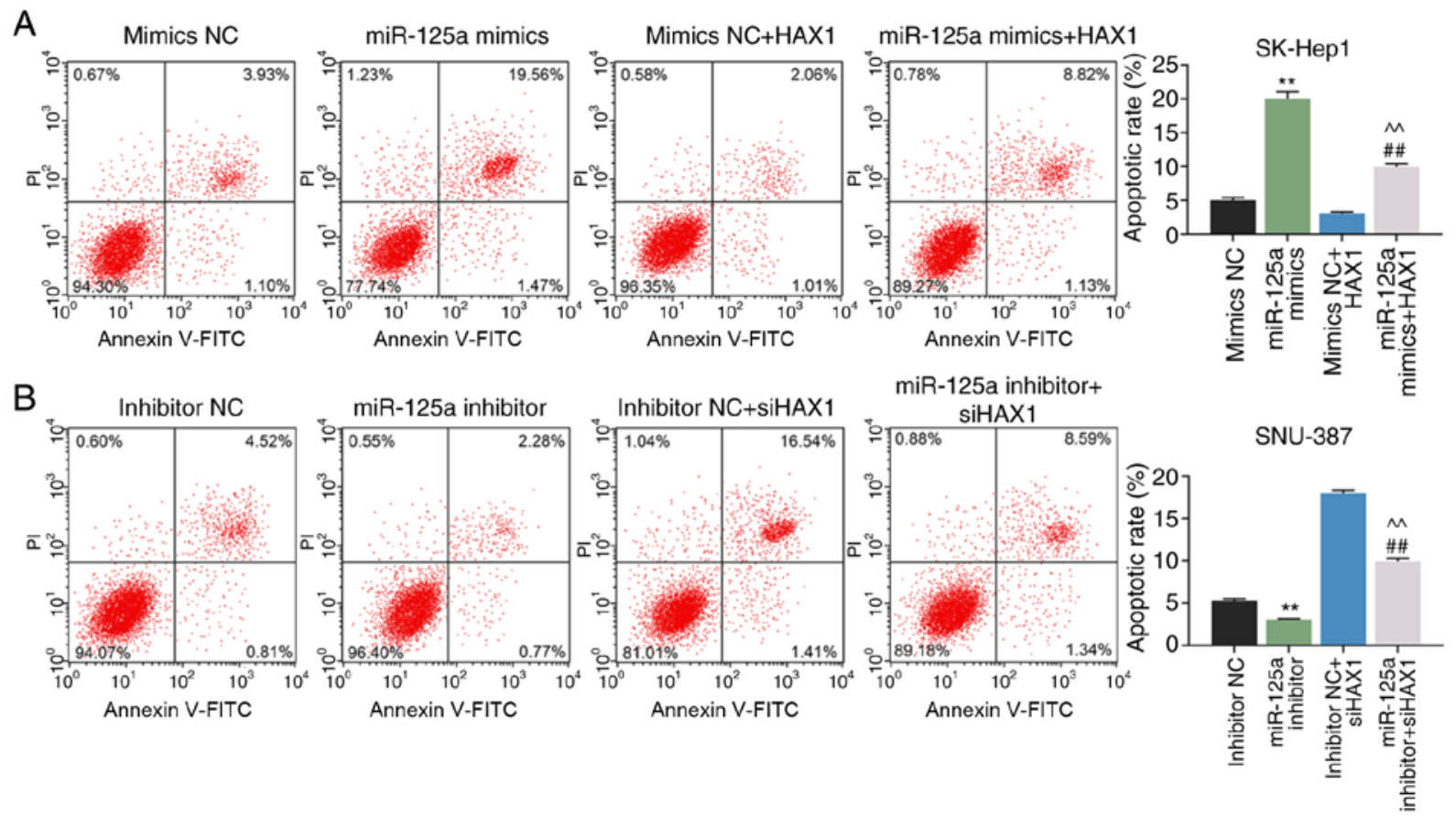

Figure 7. HAX1 reverses the effects of miR-125a on the apoptosis of SK-Hep1 and SNU-387 cells. Apoptosis of (A) SK-Hep1 was detected by Annexin V and PI staining on flow cytometry. ${ }^{* *} \mathrm{P}<0.01$ vs. mimic NC. ${ }^{\# \prime} \mathrm{P}<0.01$ vs. miR-125a mimics. ${ }^{\wedge} \mathrm{P}<0.01$ vs. mimics NC $+\mathrm{HAX}$. (B) Apoptosis of SNU-387 was detected by Annexin V and PI staining on flow cytometry. ${ }^{* *} \mathrm{P}<0.01$ vs. inhibitor NC. ${ }^{\# \#} \mathrm{P}<0.01$ vs. miR-125a inhibitor. ${ }^{\wedge} \mathrm{P}<0.01$ vs. inhibitor NC + siHAX1. Data are shown as the mean \pm standard deviation. HAX1, hematopoietic-substrate-1-associated protein X-1; miR, microRNA; si, small interfering RNA; NC, negative control.

48 h (Fig. 2B; $\mathrm{P}<0.05$ or $\mathrm{P}<0.01$ ), migration at $24 \mathrm{~h}$ (Fig. $2 \mathrm{C}$; $\mathrm{P}<0.01)$, invasion at $24 \mathrm{~h}($ Fig. $2 \mathrm{D} ; \mathrm{P}<0.01)$ and colony formation at $24 \mathrm{~h}$ (Fig. 2E; P<0.01).

HAX1 overexpression promotes the viability, migration, invasion and colony formation of SNU-387 cells. SNU-387 cells were transfected with pcDNA3.1-HAX1 plasmid to upregulate HAX1 expression, and cells transfected with pcDNA3.1 empty plasmid as were used as the negative control. RT-qPCR results revealed that HAX1 expression was significantly higher in the HAX1 group compared with the NC group (Fig. 3A; $\mathrm{P}<0.01$ ). As shown in Fig. 3B-E, compared with the NC group, HAX1 overexpression significantly promoted cell viability at 24 and $48 \mathrm{~h}$ (Fig. $3 \mathrm{~B} ; \mathrm{P}<0.05$ or $\mathrm{P}<0.01$ ), migration at $24 \mathrm{~h}$ (Fig. 3C; $\mathrm{P}<0.01$ ), invasion at $24 \mathrm{~h}$ (Fig. 3D; $\mathrm{P}<0.01)$ and colony formation at $24 \mathrm{~h}$ (Fig. $3 \mathrm{E} ; \mathrm{P}<0.01)$.

HAX1 is a target gene of miR-125a-5p. TargetScan predicted that miR-125a-5p and miR-223-3p could bind to the HAX1 3'-UTR (Fig. 4A). Dual-luciferase reporter assay demonstrated that miR-125amimics significantly inhibited the luciferase activity of the HAX1-3'-UTR (Fig. 4B; P<0.01), but did not affect HAX1-3'-UTR mut (Fig. 4B), whereas miR-223 mimics only slightly altered the luciferase activity of HAX1-3'-UTR (Fig. 4C). This indicated that the binding capacity of miR-125a to HAX1-3'-UTR was stronger compared with miR-223, thus miR-125a was seen as the target gene and investigated in subsequent experiments.

$H A X 1$ reverses the effects of $m i R-125 a-5 p$ on the viability, migration, invasion and colony formation of SK-Hepl cells. RT-qPCR results revealed that miR-125a mimics significantly promoted miR-125a expression in SK-Hep1 cells (Fig. 5A; $\mathrm{P}<0.01$ ) but did not affect miR-223 expression (Fig. 5A). miR-125a inhibitor significantly inhibited miR-125a expression in SNU-387 cells (Fig. 5B; $\mathrm{P}<0.01$ ) but exerted no effects on miR-223 expression (Fig. 5B). Compared with mimic NC, miR-125a mimics inhibited the cell viability of SK-Hep1 cells at 24 (Fig. 5C; $\mathrm{P}<0.05$ ) and $48 \mathrm{~h}$ (Fig. 5C, P<0.01). However, the effects were reversed by HAX1 overexpression (Fig. 5C; $\mathrm{P}<0.05$ or $\mathrm{P}<0.01)$. miR-125a inhibitor promoted the cell viability of SNU-387 cells at 24 and $48 \mathrm{~h}$ (Fig. 5C; $\mathrm{P}<0.01$ ), but the effect was reversed by HAX1 silencing (Fig. 5C; $\mathrm{P}<0.01$ ). Compared with the mimics NC group, miR-125a mimics significantly inhibited cell migration (Fig. 6A; $\mathrm{P}<0.01$ ), invasion (Fig. 6C; $\mathrm{P}<0.01$ ) and colony formation (Fig. 6E; $\mathrm{P}<0.01$ ), which were significantly reversed by HAX1 overexpression (Fig. 6A, C and E; P<0.01). miR-125a inhibitor significantly increased cell migration (Fig. 6B; $\mathrm{P}<0.01$ ), invasion (Fig. 6D; $\mathrm{P}<0.01$ ) and colony formation (Fig. 6F; $\mathrm{P}<0.01$ ) compared with the inhibitor NC groups. However, these effects were significantly reversed by HAX1 silencing (Fig. 6B, D and F; $\mathrm{P}<0.01)$.

$H A X 1$ reverses the effects of $m i R-125 a-5 p$ on cell apoptosis. The effects of miR-125a-5p on cell apoptosis was detected using flow cytometry. Compared with the mimics NC group, the results showed that miR-125a-5p overexpression significantly increased the apoptosis of the SK-Hep1 cells, which was partially reserved by HAX1 overexpression (Fig. 7A; $\mathrm{P}<0.01)$. The apoptosis of SNU-387 cells was decreased in the miR-125a-5p inhibitor group compared with the inhibitor NC group (Fig. 7B; $\mathrm{P}<0.01$ ), and silencing HAX1 significantly increased the apoptosis in the miR-125a-5p inhibitor + 
A
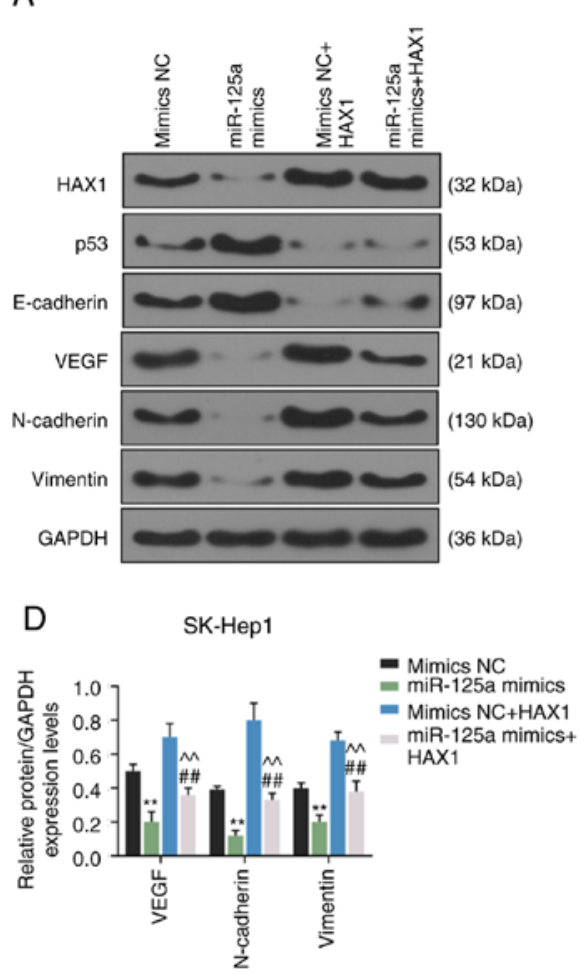

$\mathrm{F}$
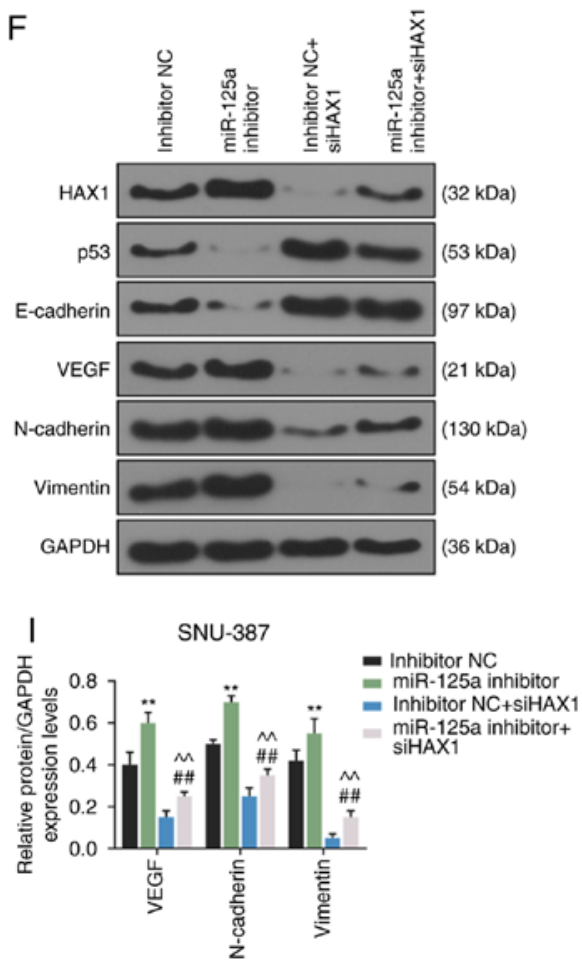

B

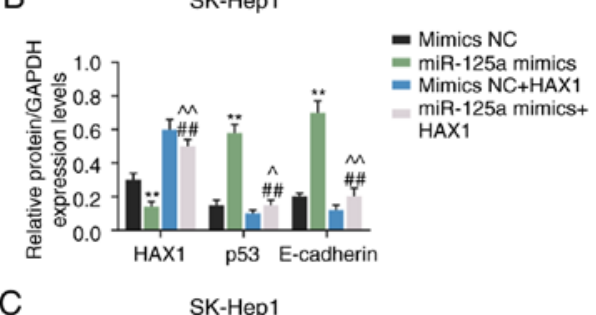

C

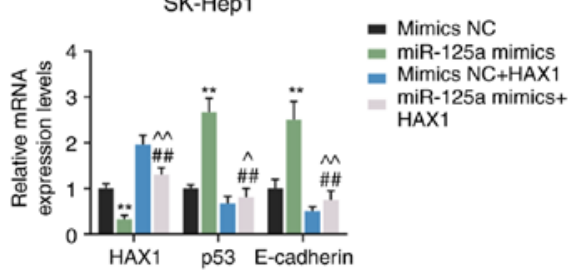

E

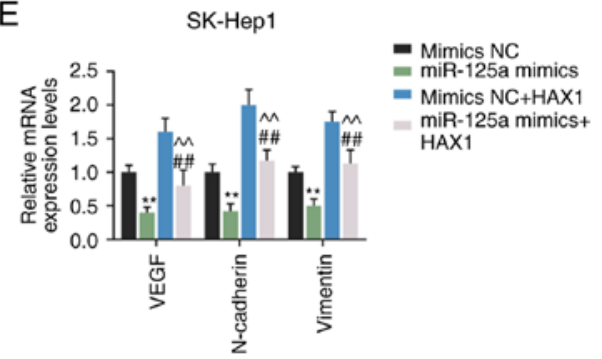

G

SNU-387

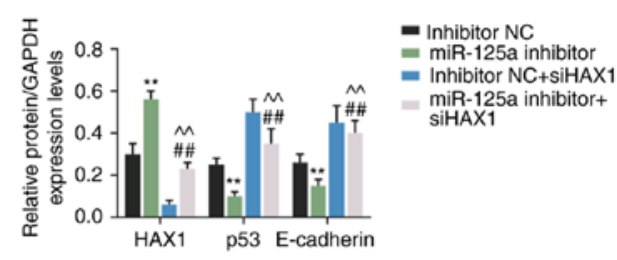

$\mathrm{H}$

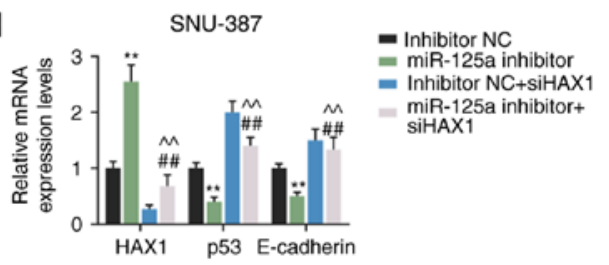

$J$

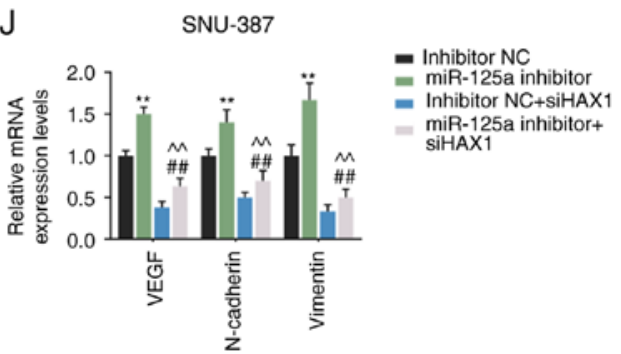

Figure 8. HAX1 reverses the effects of miR-125a-5p on the expression of p53, VEGF, and E-cadherin, N-cadherin, and vimentin in SK-Hep1 and SNU-387 cells. (A) The protein expression of HAX1, p53, E-cadherin, VEGF, N-cadherin and vimentin in SK-Hep1 cells transfected with miR-125a mimics or HAX1 or co-transfected with miR-125a mimics and HAX1 were determined by western blotting. (B) Quantification of HAX1, p53 and E-cadherin protein expression. (C) The mRNA expression of HAX1, p53 and E-cadherin in SK-Hep1 cells transfected with miR-125a mimics or HAX1 or co-transfected with miR-125a mimics and HAX1 were detected by RT-qPCR. (D) Quantification of VEGF, N-cadherin and vimentin protein expression. (E) The mRNA expression of VEGF, N-cadherin and vimentin in SK-Hep1 cells transfected with miR-125a mimics or HAX1 or co-transfected with miR-125a mimics and HAX1 were detected by RT-qPCR. ${ }^{* *} \mathrm{P}<0.01$ vs. mimics NC. ${ }^{\# \prime} \mathrm{P}<0.01$ vs. miR-125a mimics. ${ }^{\wedge} \mathrm{P}<0.05$ and ${ }^{\wedge} \mathrm{P}<0.01$ vs. mimics NC $+\mathrm{HAX} 1$. (F) The protein expression of HAX1, p53, E-cadherin, VEGF, N-cadherin and vimentin in SNU-387 cells transfected with miR-125a inhibitor or siHAX1 or co-transfected with miR-125a inhibitor and siHAX1 were determined by western blotting. (G) Quantification of HAX1, p53 and E-cadherin protein expression. (H) The mRNA expression of HAX1, p53 and E-cadherin in SNU-387 cells transfected with miR-125a inhibitor or siHAX1 or co-transfected with miR-125a inhibitor and siHAX1 were determined by RT-qPCR. (I) Quantification of VEGF, N-cadherin and vimentin protein expression (J) The mRNA expression of VEGF, N-cadherin and vimentin in SNU-387 cells transfected with miR-125a inhibitor or siHAX1 or co-transfected with miR-125a inhibitor and siHAX1 were determined by RT-qPCR. GAPDH was used as an internal control. ${ }^{* *} \mathrm{P}<0.01$ vs. inhibitor NC. ${ }^{\# \#} \mathrm{P}<0.01$ vs. miR-125a inhibitor. ${ }^{\wedge} \mathrm{P}<0.01$ vs. inhibitor NC + siHAX1. Data are shown as the mean \pm standard deviation. HAX1, hematopoietic-substrate-1-associated protein X-1; miR, microRNA; si, small interfering RNA NC, negative control; RT-qPCR, reverse transcription-quantitative PCR. 
siHAX1 group compared with the miR-125a-5p inhibitor group (Fig. 7B; P<0.01).

$H A X 1$ reverses the effects of miR-125a-5p on the expression of p53,VEGF, E-cadherin, $N$-cadherin and vimentin in SK-Hepl and SNU-387 cells. As shown in Fig. 8A-E, compared with the mimic NC group, miR-125a-5p overexpression significantly suppressed the protein and mRNA expression of HAX1 $(\mathrm{P}<0.01)$, VEGF $(\mathrm{P}<0.01)$, N-cadherin $(\mathrm{P}<0.01)$ and vimentin $(\mathrm{P}<0.01)$, and increased the protein and mRNA expression of p53 $(\mathrm{P}<0.01)$ and $\mathrm{E}$-cadherin $(\mathrm{P}<0.01)$ in SK-Hep1 cells. However, these effects were significantly reversed by HAX1 overexpression $(\mathrm{P}<0.01)$. As shown in Fig. 8F-J, miR-125a-5p silencing significantly increased the protein and mRNA levels of HAX1 $(\mathrm{P}<0.01)$, VEGF $(\mathrm{P}<0.01)$, $\mathrm{N}$-cadherin $(\mathrm{P}<0.01)$ and vimentin $(\mathrm{P}<0.01)$, and decreased the protein and mRNA levels of p53 $(\mathrm{P}<0.01)$ and $\mathrm{E}$-cadherin $(\mathrm{P}<0.01)$ in SNU-387 cells. However, the effects were significantly reversed by downregulation of HAX1 $(\mathrm{P}<0.01)$.

\section{Discussion}

HAX1 is a prognostic factor and is abnormally expressed in several types of cancer (31-33). Similar to previous results (34), the present data suggested that high HAX1 expression was associated with poorer prognosis in the liver cancer tissues and cell lines examined. The data demonstrated that HAX1 might be an oncogene for liver cancer progression and have diagnostic and prognostic values for liver cancer.

Tumor cell migration refers to directed cell movement within the body, while cancer invasion is the penetration of tumor cells through tissue barriers (35). The migration and invasion of cancer cells into surrounding tissues and vasculatures are important factors for initiating cancer metastasis (36). Tumor metastasis will result in less desired treatment outcomes of patients with liver cancer (37). The present data suggested that upregulated HAX1 expression promoted the growth, migration and invasion of liver cancer cells, whereas HAX1 knockdown produced the opposite effects, which were in accordance with the results of previous studies $(17,34)$. The present data further confirmed that HAX1 is a tumor oncogene of liver cancer development and might be an underlying target for the treatment of liver cancer.

The upstream target of HAX1 in the progression of liver cancer was examined. Different miRNAs may participate in the control of a same mRNA molecule (38). Bioinformatics analysis predicted that both miR-125a-5p and miR-223-3p could bind to HAX1. However, the results of the dual-luciferase reporter assay revealed that only miR-125a-5p can bind to HAX1, which verified that HAX1 was the target of miR-125a-5p. Several reports demonstrated that miR-125a-5p functions as a tumor suppressor in different cancers by downregulating the expression of its downstream target (39-42). In prostate carcinoma, $\mathrm{Fu}$ and Cao (43) indicated that miR-125a-5p modulates cancer cell proliferation and migration via targeting nuclear apoptosis-inducing factor 1. Tang et al (44) reported that miR-125a-5p suppresses EMT, invasion and migration of colorectal cancer cells via targeting transcriptional activator with PDZ-binding domain. In human cervical carcinoma, Qin et al (45) suggested that miR-125a-5p regulates the proliferation and migration of human cervical carcinoma cells by targeting tyrosine-protein kinase ABL2. To the best of our knowledge, the present study was the first to report that upregulated miR-125a-5p suppressed cell growth, migration and invasion of SK-Hep1 cells through inhibiting HAX1 expression, whereas downregulated miR-125a-5p produced the opposite results in SNU-387 cells through promoting HAX1 expression. These novel findings extended our previous understanding on liver cancer. In addition, Potenza et al (46) found that upregulation of miR-125a suppressed the proliferation of liver cancer cells by inhibition of sirtuin-7, which is a NAD(+)-dependent deacetylase, and induced cell cycle arrest in the G1 phase; Kim et al (47) also found that ectopic expression of miR-125a-5p and miR-125b caused growth retardation by cell cycle arrest. However, the effect of miR-125a/HAX1 on THE cell cycle of liver cancer was not detected in the current study.

p53 is a tumor suppressor that suppresses VEGF expression, tumor growth and metastasis (48). Zhou et al (49) demonstrated that miR-141-3p promoted glioma cell growth via targeting p53. VEGF is considered as a potent angiogenic mitogen and able to induce tumor angiogenesis (50). Angiogenesis is a process of developing and forming new blood vessels, and plays an important role in tumor growth and metastasis (51). In laryngeal cancer, Zhang et al (52) demonstrated that downregulated miR-206 promoted the proliferation and invasion of cancer cells by modulating VEGF expression. Wu et al (53) suggested that miR-125 suppressed cell growth of RKO colorectal cancer cells via targeting VEGF. It was reported that the EMT process is involved in the migration and invasion of cancer cells and plays a critical role in cancer metastasis $(54,55)$. Decreased E-cadherin expression and increased $\mathrm{N}$-cadherin expression are indicative of EMT (56). Vimentin, an EMT marker, is widely found in normal mesenchymal cells and maintains cellular integrity (57). The expression of p53, VEGF, E-cadherin, N-cadherin and vimentin were detected to assess the mechanism underlying the effects of miR-125a-5p on cell growth, migration and invasion via targeting HAX1. The present findings showed that miR-125a-5p overexpression increased the expression of p53 and E-cadherin, and suppressed the expression of VEGF, N-Cadherin, and Vimentin in SK-Hep1 cells via inhibiting HAX1 expression, while downregulated miR-125a-5p produced the opposite effects in SNU-387 cells via promoting HAX1 expression. The results suggested that miR-125a-5p regulated cell growth, migration and invasion via directly targeting HAX1, which might be dependent on the regulation of p53 and VEGF expression and the EMT process.

The present results revealed the effects and the underlying molecular mechanism of HAX1 on liver cancer progression. However, the present study also has some limitations. Although the present findings developed the current understanding the pathogenesis of liver cancer and discovered a novel target for the treatment of liver cancer, the function of the miR-125a/HAX1 axis should be further verified in vivo. Moreover, whether mir-125a/HAX1 can affect the role of hepatocellular carcinoma drugs by regulating certain signaling pathways remain to be determined.

Taken together, HAX1 acts as a tumor oncogene in liver cancer. miR-125a-5p regulated the viability, colony formation, migration and invasion of liver cancer cells by negatively regulating HAX1 expression. The process also involves the expression of p53, VEGF and EMT. 


\section{Acknowledgements}

Not applicable.

\section{Funding}

This work was supported by the Joint Project of Provincial Health Department (grant no. LHGJ20191222).

\section{Availability of data and materials}

The datasets used and/or analyzed during the current study are available from the corresponding author on reasonable request.

\section{Authors' contributions}

ZZ designed the study. JL performed the experiments and contributed to data analysis. ZZ drafted and revised the article. All authors gave final approval of the version to be published and agree to be accountable for all aspects of the work.

\section{Ethics approval and consent to participate}

The present study was approved by the Ethics Committee of the Luoyang Central Hospital Affiliated to Zhengzhou University (approval no. LC20170416022). All patients signed informed consent in any experimental work involving human samples.

\section{Patient consent for publication}

Not applicable.

\section{Competing interests}

The authors declare that they have no competing interests.

\section{References}

1. Costentin C: Hepatocellular carcinoma surveillance. Presse Med 46: 381-385, 2017 (In French).

2. Alsaied OA, Sangwan V, Banerjee S, Krosch TC, Chugh R, Saluja A, Vickers SM and Jensen EH: Sorafenib and triptolide as combination therapy for hepatocellular carcinoma. Surgery 156: 270-279, 2014

3. Zhu ZX, Huang JW, Liao MH and Zeng Y: Treatment strategy for hepatocellular carcinoma in China: Radiofrequency ablation versus liver resection. Jpn J Clin Oncol 46: 1075-1080, 2016.

4. Forner A, Reig M and Bruix J: Hepatocellular carcinoma. Lancet 391: 1301-1314, 2018.

5. Zhang Y, Huang F, Wang J, Peng L and Luo H: MiR-15b mediates liver cancer cells proliferation through targeting BCL-2. Int J Clin Exp Pathol 8: 15677-15683, 2015.

6. Liu CY, Chen KF and Chen PJ: Treatment of liver cancer. Cold Spring Harb Perspect Med 5: a021535, 2015.

7. Llovet JM, Schwartz M and Mazzaferro V: Resection and liver transplantation for hepatocellular carcinoma. Semin Liver Dis 25: 181-200, 2005.

8. Guo M, Zhang H, Zheng J and Liu Y: Glypican-3: A new target for diagnosis and treatment of hepatocellular carcinoma. J Cancer 11: 2008-2021, 2020.

9. Balcerak A, Trebinska-Stryjewska A, Wakula M, Chmielarczyk M, Smietanka U, Rubel T, Konopinski R, Macech-Klicka E, Zub R and Grzybowska EA: HAX1 impact on collective cell migration, cell adhesion, and cell shape is linked to the regulation of actomyosin contractility. Mol Biol Cell 30: 3024-3036, 2019.
10. Bidwell PA, Liu GS, Nagarajan N, Lam CK, Haghighi K, Gardner G, Cai WF, Zhao W, Mugge L, Vafiadaki E, et al: HAX-1 regulates SERCA2a oxidation and degradation. J Mol Cell Cardiol 114: 220-233, 2018.

11. Fadeel B and Grzybowska E: HAX-1: A multifunctional protein with emerging roles in human disease. Biochim Biophys Acta 1790: 1139-1148, 2009.

12. Wei XJ, Li SY, Yu B, Chen G, Du JF and Cai HY: Expression of HAX-1 in human colorectal cancer and its clinical significance. Tumour Biol 35: 1411-1415, 2014.

13. Li X, Li T, You B, Shan Y, Shi S, Cao X and Qian L: Expression and function of HAX-1 in human cutaneous squamous cell carcinoma. J Cancer 6: 351-359, 2015.

14. You Y, Yao H, You B, Li X, Ni H, Shi S, Shan Y and Cao X: Clinical significance of HAX-1 expression in laryngeal carcinoma. Auris Nasus Larynx 42: 299-304, 2015.

15. Feng X, Kwiecinska A, Rossmann E, Bottai M, Ishikawa T, Patarroyo M, Österborg A, Porwit A, Zheng C and Fadeel B: HAX-1 overexpression in multiple myeloma is associated with poor survival. Br J Haematol 185: 179-183, 2019.

16. Ramsay AG, Keppler MD, Jazayeri M, Thomas GJ, Parsons M, Violette S, Weinreb P, Hart IR and Marshall JF: HS1-associated protein X-1 regulates carcinoma cell migration and invasion via clathrin-mediated endocytosis of integrin alphavbeta6. Cancer Res 67: 5275-5284, 2007.

17. Wang Y, Huo X, Cao Z, Xu H, Zhu J, Qian L, Fu H and Xu B: HAX-1 is overexpressed in hepatocellular carcinoma and promotes cell proliferation. Int J Clin Exp Pathol 8: 8099-8106, 2015.

18. Banerjee A, Saito K, Meyer K, Banerjee S, Ait-Goughoulte M, Ray RB and Ray R: Hepatitis C virus core protein and cellular protein HAX-1 promote 5-fluorouracil-mediated hepatocyte growth inhibition. J Virol 83: 9663-9671, 2009.

19. Liu W, Cui Z and Zan X: Identifying cancer-related microRNAs based on subpathways. IET Syst Biol 12: 273-278, 2018.

20. Bartel DP: MicroRNAs: Target recognition and regulatory functions. Cell 136: 215-233, 2009.

21. Gandhi NS, Tekade RK and Chougule MB: Nanocarrier mediated delivery of siRNA/miRNA in combination with chemotherapeutic agents for cancer therapy: Current progress and advances. J Control Release 194: 238-256, 2014.

22. Gallach S, Calabuig-Farinas S, Jantus-Lewintre E and Camps C: MicroRNAs: Promising new antiangiogenic targets in cancer. Biomed Res Int 2014: 878450, 2014.

23. Li E, Ji P, Ouyang N,Zhang Y, Wang XY, Rubin DC, Davidson NO, Bergamaschi R, Shroyer KR, Burke S, et al: Differential expression of miRNAs in colon cancer between African and Caucasian Americans: Implications for cancer racial health disparities. Int J Oncol 45: 587-594, 2014.

24. Nishida N, Mimori K, Fabbri M, Yokobori T, Sudo T, Tanaka F, Shibata K, Ishii H, Doki Y and Mori M: MicroRNA-125a-5p is an independent prognostic factor in gastric cancer and inhibits the proliferation of human gastric cancer cells in combination with trastuzumab. Clin Cancer Res 17: 2725-2733, 2011.

25. Li G, Zhang W, Gong L and Huang X: MicroRNA 125a-5p inhibits cell proliferation and induces apoptosis in hepatitis $\mathrm{B}$ virus-related hepatocellular carcinoma by downregulation of ErbB3. Oncol Res 27: 449-458, 2019.

26. Cai M, Chen Q, Shen J, Lv C and Cai L: Epigenetic silenced miR-125a-5p could be self-activated through targeting Suv39H1 in gastric cancer. J Cell Mol Med 22: 4721-4731, 2018.

27. Bi Q, Tang S, Xia L, Du R, Fan R, Gao L, Jin J, Liang S, Chen Z, $\mathrm{Xu} \mathrm{G}$, et al: Ectopic expression of MiR-125a inhibits the proliferation and metastasis of hepatocellular carcinoma by targeting MMP11 and VEGF. PLoS One 7: e40169, 2012.

28. Menyhárt O, Nagy Á and Győrffy B: Determining consistent prognostic biomarkers of overall survival and vascular invasion in hepatocellular carcinoma. R Soc Open Sci 5: 181006, 2018.

29. Ke Q, Ji J, Cheng C, Zhang Y, Lu M, Wang Y, Zhang L, Li P, Cui X, Chen L, et al: Expression and prognostic role of Spyl as a novel cell cycle protein in hepatocellular carcinoma. Exp Mol Pathol 87: 167-172, 2009.

30. Livak KJ and Schmittgen TD: Analysis of relative gene expression data using real-time quantitative PCR and the 2(-Delta Delta C(T)) method. Methods 25: 402-408, 2001.

31. Sheng $\mathrm{C}$ and Ni Q: Expression of HAX1 and Ki-67 in breast cancer and its correlations with patient's clinicopathological characteristics and prognosis. Int J Clin Exp Med 8: 20904-20910, 2015. 
32. Li M, Tang Y, Zang W, Xuan X, Wang N, Ma Y, Wang Y, Dong Z and Zhao G: Analysis of HAX-1 gene expression in esophageal squamous cell carcinoma. Diagn Pathol 8: 47, 2013.

33. Deng X, Song L, Wei Y and Guo XB: Analysis of the expression of HAX-1 gene in human glioma. Neurosci Lett 657: 189-193, 2017.

34. Wu Z, Ai X, Hu H, Wang S, Wang Y, Kang F, Ouyang C and Zhu J: Hematopoietic-substrate-1 associated protein X-1 (HAX-1) regulates liver cancer cells growth, metastasis, and angiogenesis through Akt. Cancer Biol Ther 20: 1223-1233, 2019.

35. Kramer N, Walzl A, Unger C, Rosner M, Krupitza G, Hengstschläger $M$ and Dolznig $\mathrm{H}$ : In vitro cell migration and invasion assays. Mutat Res 752: 10-24, 2013.

36. Duff D and Long A: Roles for RACK1 in cancer cell migration and invasion. Cell Signal 35: 250-255, 2017.

37. Hua L, Wang CY, Yao KH, Chen JT, Zhang JJ and Ma WL: High expression of long non-coding RNA ANRIL is associated with poor prognosis in hepatocellular carcinoma. Int J Clin Exp Pathol 8: 3076-3082, 2015.

38. Shan H, Zhou X and Chen C: MicroRNA214 suppresses the viability, migration and invasion of human colorectal carcinoma cells via targeting transglutaminase 2 . Mol Med Rep 20 1459-1467, 2019.

39. Yan L, Yu MC, Gao GL, Liang HW, Zhou XY, Zhu ZT, Zhang CY, Wang YB and Chen X: MiR-125a-5p functions as a tumour suppressor in breast cancer by downregulating BAP1. J Cell Biochem 119: 8773-8783, 2018.

40. Yang X, Qiu J, Kang H, Wang Y and Qian J: miR-125a-5p suppresses colorectal cancer progression by targeting VEGFA. Cancer Manag Res 10: 5839-5853, 2018.

41. Zhang Y, Zhang D, Lv J, Wang S and Zhang Q: MiR-125a-5p suppresses bladder cancer progression through targeting FUT4. Biomed Pharmacother 108: 1039-1047, 2018.

42. Zhong L, Sun S, Shi J, Cao F, Han X and Chen Z: MicroRNA-125a-5p plays a role as a tumor suppressor in lung carcinoma cells by directly targeting STAT3. Tumour Biol 39: $1010428317697579,2017$.

43. Fu Y and Cao F: MicroRNA-125a-5p regulates cancer cell proliferation and migration through NAIF1 in prostate carcinoma Onco Targets Ther 8: 3827-3835, 2015.

44. Tang L, Zhou L, Wu S, Shi X, Jiang G, Niu S and Ding D miR-125a-5p inhibits colorectal cancer cell epithelial-mesenchymal transition, invasion and migration by targeting TAZ. Onco Targets Ther 12: 3481-3489, 2019.

45. Qin X, Wan Y, Wang S and Xue M: MicroRNA-125a-5p modulates human cervical carcinoma proliferation and migration by targeting ABL2. Drug Des Devel Ther 10: 71-79, 2015.
46. Potenza N, Mosca N, Zappavigna S, Castiello F, Panella M, Ferri C, Vanacore D, Giordano A, Stiuso P, Caraglia M and Russo A: MicroRNA-125a-5p is a downstream effector of sorafenib in its antiproliferative activity toward human hepatocellular carcinoma cells. J Cell Physiol 232: 1907-1913, 2017.

47. Kim JK, Noh JH, Jung KH, Eun JW, Bae HJ, Kim MG, Chang YG, Shen Q, Park WS, Lee JY, et al: Sirtuin7 oncogenic potential in human hepatocellular carcinoma and its regulation by the tumor suppressors MiR-125a-5p and MiR-125b. Hepatology 57: 1055-1067, 2013

48. Yu YF, Zhang Y, Shen N, Zhang RY and Lu XQ: Effect of VEGF, $\mathrm{P} 53$ and telomerase on angiogenesis of gastric carcinoma tissue. Asian Pac J Trop Med 7: 293-296, 2014

49. Zhou X, Wu W, Zeng A, Nie E, Jin X, Yu T, Zhi T, Jiang K, Wang Y, Zhang J and You Y: MicroRNA-141-3p promotes glioma cell growth and temozolomide resistance by directly targeting p53. Oncotarget 8: 71080-71094, 2017.

50. Leung DW, Cachianes G, Kuang WJ, Goeddel DV and Ferrara N Vascular endothelial growth factor is a secreted angiogenic mitogen. Science 246: 1306-1309, 1989.

51. Folkman $\mathrm{J}$ : What is the evidence that tumors are angiogenesis dependent? J Natl Cancer Inst 82: 4-6, 1990.

52. Zhang T, Liu M, Wang C, Lin C, Sun Y and Jin D: Down-regulation of MiR-206 promotes proliferation and invasion of laryngeal cancer by regulating VEGF expression. Anticancer Res 31: 3859-3863, 2011

53. Wu QB, Chen J, Zhu JW, Yin X, You HY, Lin YR and Zhu HQ MicroRNA-125 inhibits RKO colorectal cancer cell growth by targeting VEGF. Int J Mol Med 42: 665-673, 2018.

54. Jakobsen KR, Demuth C, Sorensen BS and Nielsen AL: The role of epithelial to mesenchymal transition in resistance to epidermal growth factor receptor tyrosine kinase inhibitors in non-small cell lung cancer. Transl Lung Cancer Res 5: 172-182, 2016.

55. Xiao Z, Chen M, Yang J, Yang C, Lü X, Tian H and Liu C: MTBP regulates migration and invasion of prostate cancer cells in vitro. Nan Fang Yi Ke Da Xue Xue Bao 39: 6-12, 2019 (In Chinese).

56. Ramamurthy VP, Ramalingam S, Gediya LK and Njar VCO: The retinamide VNLG-152 inhibits f-AR/AR-V7 and MNK-eIF4E signaling pathways to suppress EMT and castration-resistant prostate cancer xenograft growth. FEBS J 285: 1051-1063, 2018.

57. Satelli A and Li S: Vimentin in cancer and its potential as a molecular target for cancer therapy. Cell Mol Life Sci 68: 3033-3046, 2011

This work is licensed under a Creative Commons Attribution-NonCommercial-NoDerivatives 4.0 International (CC BY-NC-ND 4.0) License. 